\title{
Cardiovascular secondary prevention in primary care setting: an immediate necessity in Brazil and worldwide
}

\author{
Paulo Andrade Lotufo' \\ Faculdade de Medicina da Universidade de São Paulo (FMUSP), São Paulo (SP), Brazil
}

'MD, DrPH. Full Professor, Department of Internal Medicine, Faculdade de Medicina da Universidade de São Paulo (FMUSP), São Paulo (SP), Brazil. (Dorcid.org/0000-0002-4856-8450
Cardiovascular diseases (CVD) such as coronary heart disease, stroke and peripheral arterial diseases are the leading causes of death worldwide. ${ }^{1}$ The decline in age-adjusted mortality rates observed since the late 1960 s was initially attributed partially to two concomitant factors. First, case-fatality rates have decreased due to better awareness of early symptoms and introduction of pre-hospital care, coronary care units, new drugs and surgical interventions. Second, reduction in the numbers of cigarettes smoked per day (smoking has been correlated with sudden death due to cardiac arrest) and lowering of very high blood pressures (hypertension has been correlated with massive hemorrhagic stroke) have played a significant role in reducing the risk of death due to cardiovascular diseases. ${ }^{2}$ However, in contrast to assessments on mortality data, finding information about the incidence of CVDs is not an easy task. There are few empirical population-based studies, and extrapolation from mortality data with the aim of calculating incidence is insufficient.

We make the assumption that reductions in new-onset CVD cases are not occurring worldwide, or at least at the same pace observed for death rates. This assumption can be explained in terms of lifestyle changes that occurred during the 1990s. Primordial prevention (smoking bans, greater availability of healthy foods and encouragement of leisure-time physical activity) and more adequate primary prevention such as control of high blood pressure and high cholesterol became a reality. ${ }^{3}$ However, a new factor rapidly spread worldwide: the epidemic of obesity and diabetes, which has increased the number of people prone to CVD events. ${ }^{4}$

If the rates of new-onset cardiovascular diseases do not decline, but the case-fatality rates drop, the prevalence of people with CVD should consequently increase. The confluence of these movements (declining lethality, stable incidence and rising obesity) has increased the numbers of survivors from myocardial infarction and stroke. These individuals, together with the pool of people with angina pectoris and peripheral artery disease, are responsible for the increase in cardiovascular disease prevalence rates. Data from the 2013 Brazilian National Health Survey and the Brazilian Longitudinal Study of Adult Health (ELSA-Brasil) revealed that higher prevalence of these conditions was strongly associated with lower socioeconomic status ${ }^{5-7}$ (Table 1). Consequently, the prevalence of individuals who can be assigned to secondary prevention is growing mainly among the poorest.

Although the benefits of secondary prevention measures (lifestyle changes, blood pressure control and use of aspirin and statins) to reduce health-adverse cardiovascular events is undisputable, ${ }^{8}$ these measures have not been adopted worldwide. In the Prospective Urban Rural Epidemiological (PURE) study, data on 153,996 adults with CVDs (aged 35-70 years) who were living in countries at different stages of economic development were analyzed. Comparing South America with North America/Europe, the rates of use of medications of proven effectiveness for people with coronary heart diseases (CHDs) or stroke were, respectively, 29\% versus $52 \%$ for antiplatelet drugs; $58 \%$ versus $69 \%$ for blood pressure lowering agents; and $15 \%$ versus $52 \%$ for statins. ${ }^{9}$ One explanation for these results is that neither outpatient cardiological units, nor primary care facilities in South America have adopted trustworthy programs for secondary prevention as a public health policy. 
Table 1. Prevalence ratios (and $95 \%$ confidence intervals) according to level of education, for heart diseases, angina and stroke from the 2013 Brazilian National Health Survey (NHS) and for peripheral artery disease from the Brazilian Longitudinal Study of Adult Health (ELSA-Brasil) ${ }^{5-7}$

\begin{tabular}{lcccc} 
Education & \multicolumn{3}{c}{$2013 \mathrm{NHS}(\mathrm{n}=60,202)$} & $\begin{array}{c}\text { ELSA-Brasil } \\
(\mathrm{n}=15,105)\end{array}$ \\
\cline { 2 - 5 } \begin{tabular}{l} 
level \\
\cline { 2 - 5 }
\end{tabular} & $\begin{array}{c}\text { Heart } \\
\text { disease }\end{array}$ & $\begin{array}{c}\text { Angina } \\
\text { pectoris }\end{array}$ & Stroke & $\begin{array}{c}\text { Peripheral } \\
\text { artery disease }\end{array}$ \\
\hline $\begin{array}{l}\text { Less than } \\
\text { elementary }\end{array}$ & $6.3(5.7-6.9)$ & $10.8(10-11.5)$ & $2.7(2.4-3.1)$ & $10.1(9.5--0.6)$ \\
Elementary & $3.1(2.4-3.7)$ & $7.5(6.5-8.5)$ & $0.8(0.6-1.1)$ & $8.8(8.6-9.1)$ \\
\hline High school & $2.5(2.0-2.9)$ & $5.5(4.9-6)$ & $0.8(0.8-1)$ & $5.5(5.4-5.7)$ \\
\hline College & $3.5(2.5-4.4)$ & $3.6(2.9-14.4)$ & $0.6(0.6-0.8)$ & $5.4(5.3-5.5)$
\end{tabular}

One challenge is to test how secondary prevention as provided by several guidelines should be practiced within primary care settings. ${ }^{8}$ The problem of "secondary" (cardiovascular prevention) within the "primary" (care setting) is much more related to phraseology than to the capabilities and features of primary care units, including family health programs, which would undertake these measures immediately.

\section{REFERENCES}

1. GBD 2015 Mortality and Causes of Death Collaborators. Global, regional, and national life expectancy, all-cause mortality, and causespecific mortality for 249 causes of death, 1980-2015: a systematic analysis for the Global Burden of Disease Study 2015. Lancet. 2016;388(10053):1459-544.

2. Tunstall-Pedoe $H$, Kuulasmaa $K$, Mähönen $M$, et al. Contribution of trends in survival and coronary-event rates to changes in coronary heart disease mortality: 10-year results from 37 WHO MONICA project populations. Monitoring trends and determinants in cardiovascular disease. Lancet. 1999;353(9164):1547-57.

3. Nabel EG, Braunwald E. A tale of coronary artery disease and myocardial infarction. N Engl J Med. 2012;366(1):54-63.

4. Ng M, Fleming T, Robinson M, et al. Global, regional, and national prevalence of overweight and obesity in children and adults during 1980-2013: a systematic analysis for the Global Burden of Disease Study 2013. Lancet. 2014;384(9945):766-81.

5. Lotufo PA, Szwarcwald CL, Stopa SR, et al. Prevalência de angina do peito pelo questionário de Rose na população brasileira: análise da Pesquisa Nacional de Saúde, 2013 [Prevalence of angina pectoris in the Brazilian population from the Rose questionnaire: analysis of the National Health Survey, 2013]. Rev Bras Epidemiol. 2015;18(supl 2):123-31.

6. Bensenor IM, Vieira MLFP, Szwarcwald CL, et al. Prevalência de acidente vascular cerebral e de incapacidade associada no Brasil: Pesquisa Nacional de Saúde - 2013 [Prevalence of stroke and associated disability in Brazil: National Health Survey—2013]. Arq Neuropsiquiatr. 2015;73(9):746-50.
7. Miname M, Bensenor IM, Lotufo PA. Different methods of calculating ankle-brachial index in mid-elderly men and women: the Brazilian Longitudinal Study of Adult Health (ELSA-Brasil). Braz J Med Biol Res. 2016;49(12):e5734.

8. Smith SC Jr, Benjamin EJ, Bonow RO, et al. AHA/ACCF secondary prevention and risk reduction therapy for patients with coronary and other atherosclerotic vascular disease: 2011 update: a guideline from the American Heart Association and American College of Cardiology Foundation endorsed by the World Heart Federation and the Preventive Cardiovascular Nurses Association. J Am Coll Cardiol. 2011;58(23):2432-46.

9. Yusuf S, Islam S, Chow CK, et al. Use of secondary prevention drugs for cardiovascular disease in the community in high-income, middleincome, and low-income countries (the PURE Study): a prospective epidemiological survey. Lancet. 2011;378(9798):1231-43.

Sources of funding: Not declared

Conflict of interest: Not declared

\section{Address for correspondence:}

Paulo Andrade Lotufo

Centro de Pesquisa Clínica e Epidemiológica, Hospital Universitário, Universidade de São Paulo

Av. Prof. Lineu Prestes, 2.565

Butantã — São Paulo (SP) — Brasil

Tel. (+55 11) 3091-9300

E-mail:palotufo@usp.br 